\title{
A INTERPRETAÇÃO RICOEURIANA DA HERMENÊUTICA FILOSÓFICA DE MARTIN HEIDEGGER
}

\author{
THE RICOEURIAN INTERPRETATION OF MARTIN HEIDEGGER'S PHILOSOPHICAL \\ HERMENEUTICS
}

Frederico Soares de Almeida*

\begin{abstract}
RESUMO
Este artigo tem como objetivo apresentar a leitura ricoeuriana da hermenêutica filosófica elaborada por Martin Heidegger, pensador reconhecido por realizar o radical movimento hermenêutico da epistemologia para a ontologia. Segundo Ricoeur, a questão central nos estudos de Heidegger é o sentido do ser. É discorrendo sobre esse tema que o filósofo alemão altera e revoluciona a teoria do conhecimento, lidando com uma interrogação capaz de preceder a própria teoria e de abarcar o modo pelo qual um ser encontra o ser, antes mesmo de se opor a este como um objeto que enfrenta um sujeito. Assim, a questão do mundo ocupa o lugar da questão outrem. Ao mundanizar o compreender, Heidegger o despsicologiza. E o primado da questão hermenêutica passa a conceber a disciplina não como uma reflexão sobre as ciências do espírito, mas como uma explicitação do solo ontológico sobre o qual essas ciências podem ser edificadas. Sendo assim, a epistemologia é subordinada à ontologia. Com o desenvolvimento do pensamento heideggeriano, Ricoeur compreende o abandono do Dasein e aponta para a projeção de epistemologia subordinada à ontologia.
\end{abstract}

PALAVRAS-CHAVE: hermenêutica; Dasein; compreender.

\section{ABSTRACT}

This paper aims to present the Ricoeurian reading of the philosophical hermeneutics developed by Martin Heidegger, who is regarded as the philosopher who performed the radical hermeneutic movement from epistemology to ontology. According to Ricoeur, the fundamental question put forth by Heidegger's thought is about the sense of being. By discussing this subject, the German thinker changes and revolutionizes the theory of knowledge, dealing with an interrogation that precedes the theory itself and intends to embrace the way in which a being encounters the being, even before opposing it as an object facing a subject. Thus, the question of the world takes the place of the question of others. By mundanizing understanding, Heidegger depsychologizes it. In Heidegger, the primacy of the hermeneutic question is the understanding that hermeneutics can't be seen as a reflection of the sciences of the spirit, but as an elucidation of the ontological ground upon which such sciences can be built. Therefore, following the development of Heidegger's thought, Ricoeur understands the abandonment of Dasein and points to the projection of epistemology subordinated to ontology.

KEYWORD: hermeneutics; Dasein; understand.

\footnotetext{
* Mestre em Filosofia pela Faculdade Jesuíta de Filosofia e Teologia. Doutorando em Filosofia Contemporânea pela UFMG. E-mail: fredkrav@gmail.com.
}

Sapere aude - Belo Horizonte, v. 12 - n. 23, p. 206-2016, Jan./Jun. 2021 - ISSN: 2177-6342 


\section{INTRODUÇÃO}

A partir de Schleiermacher, a hermenêutica deixou de ser especial e passou a assumir um caráter filosófico, indagando-se por uma fundamentação universal da compreensão. Desde então, a pergunta hermenêutica ganhou um novo sentido. Ela aparecerá como arte da interpretação e ocupará lugar na filosofia, buscando entender o significado e o agir do ser humano. Em seus estudos, Schleiermacher procurou realizar a mediação entre um autor e um leitor. A partir desse empenho, a hermenêutica passou a ter, como ponto central, a busca pela intenção do autor, tornando-se, pois, psicológica.

Posteriormente, Wilhelm Dilthey procurou o traço distintivo da compreensão. Dilthey subordinou o problema hermenêutico ao problema propriamente psicológico do conhecimento de outrem. Nessa perspectiva, a compreensão está relacionada com a capacidade de se transpor à vida psíquica de outrem. Dilthey, ao levar seu projeto hermenêutico mais adiante, apresenta uma nova compreensão, a qual se caracterizará pela transição da esfera psicológica para a histórica. Dessa forma, a história universal torna-se o próprio campo hermenêutico, e a hermenêutica passa a ser vista como o acesso do indivíduo à história universal. Ocorre, pois, a universalização do próprio indivíduo. Como teoria filosófica, a hermenêutica busca justificar a validade universal das interpretações históricas, tornando-se, então, o método das ciências humanas.

No século XX, Martin Heidegger surge trazendo um novo conceito: o de facticidade. Essa noção inverterá a concepção de hermenêutica e, para ela, tornar-se-á fundamental, dando importância à valorização da experiência. Logo, o mundo, o lugar da habitação, deve ser preservado, entendido e compreendido pela humanidade; e o homem não é sujeito, mas sim dasein, sendo ontologicamente compreensão. A partir dessa ótica, Heidegger realiza a virada da hermenêutica, transformando-a em área filosófica. E é com essa transição que a filosofia de Ricoeur dialoga. Dito isso, firma-se aqui o objetivo deste artigo: apresentar a leitura que Ricoeur realiza da hermenêutica filosófica desenvolvida por Heidegger.

\section{A LEITURA RICOEURIANA DA HERMENÊUTICA FILOSÓFICA DE MARTIN HEIDEGGER}

Conforme Luiz Rohden, a virada da hermenêutica epistemológica, da teoria moderna, à ontologia inicia-se com a compreensão da hermenêutica da facticidade de Heidegger como 
campo da filosofia (ROHDEN, 2002, p. 65). Esse pensador alemão estabelece um distanciamento radical em relação às questões epistemológicas que dominaram o período de Dilthey, às quais a hermenêutica esteve atrelada, sem, contudo, ser, em si mesma, encerrada. A hermenêutica de Dilthey inscreveu-se no debate epistemológico, pois dizia respeito à "cientificidade das ciências hermenêuticas que estavam em jogo no triplo plano de determinação de seu campo, do estabelecimento de seu procedimento principal e do fundamento último de sua especificidade" (RICOEUR, 2010, p. 126). Logo, esse último aspecto conduziu a passagem da epistemologia para uma interrogação transcendental de tipo kantiano; e isso fez com que a pesquisa metodológica fosse submetida à investigação das condições de possibilidade. Diante desse contexto, emerge a filosofia de Heidegger, e ela buscará romper com todo esse modo de questionamento.

Heidegger se interessou, de início, pela justificação das ciências do espírito. A reflexão do pensador alemão será de cunho ontológico. Para ele, somos nós que nos questionamos sobre o ser. Essa radicalização não epistemológica da questão é evidente desde a introdução de Ser $e$ tempo (HEIDEGGER, 2018). Sendo assim, a interrogação inicial assume um lugar privilegiado, relacionando-se com a questão do ser que somos, o Dasein (RICOEUR, 2010, p. 126). O analítico do Dasein surge no começo apenas a título preparatório. Antes da relação de conhecimento entre um sujeito e um objeto, existe a implicação da compreensão na estrutura ontológica do ser-lançado e da antecipação (RICOEUR, 2010, p. 127-128). Assim, a questão do sentido será entendida como a questão hermenêutica por excelência. A indagação de base aristotélica suplantará a de origem kantiana. Ricoeur (1986, p. 89-90), em um certo sentido, afirmará que a ontologia impõe-se à epistemologia e essa subordinação alcançará seu lugar mais alto quando a metodologia das ciências históricas for superada por meio de um questionamento em relação à historicidade do Dasein: antes que a história venha ter um objeto e um método, somos históricos de ponta a ponta.

A hermenêutica em Heidegger pode ser entendida como o caminho que conduz à compreensão (HEIDEGGER, 2018, p. 209). Nesse sentido, a interpretação está existencialmente fundada no compreender. E essa questão, a da compreensão, está implícita na pergunta a respeito do sentido do ser: "ela mesma não é uma questão epistemológica, pelo menos a título primário" (RICOEUR, 2010, p. 127). Compreender deve ser entendido como um traço distintivo do ser que nós somos, uma propriedade do Dasein enquanto ser no mundo. A interpretação deve ser percebida como o desenvolvimento da compreensão, considerando que compreender qualquer evento como fato já é interpretá-lo. A interpretação é articulada a um 
discurso que busca determinar e esclarecer as articulações de uma situação delimitada e de uma compreensão específica que inicialmente estavam conectadas a um nível mais primordial do que o discurso. Logo, é necessário pontuar que Heidegger entende que a interpretação deve ser concebida não como tomar conhecimento do que se compreendeu, mas sim o elaborar as possibilidades projetadas no compreender. Como pontua Mac Dowell (2011, p. 10), Heidegger tem como intenção transformar a hermenêutica no método filosófico de interpretação da própria realidade. Para o filósofo alemão, o caráter hermenêutico da compreensão se relaciona ao fenômeno da verdade como des-ocultamento. Logo, o entendimento da realidade depende da perspectiva sob a qual ela é abordada. Dessa forma, quando o ente aparece no seu desocultamento, dentro de um aspecto, ele acaba se ocultando sob outro aspecto. A estrutura do compreender revela a finitude da existência humana e de seu compreender. Sendo assim, a hermenêutica heideggeriana é assimilada como a hermenêutica da facticidade.

Ricoeur observa que Heidegger trilha o caminho da via curta dentro do horizonte de fundação da hermenêutica na fenomenologia. Para aquele, essa via pode ser entendida como uma ontologia da compreensão, à maneira de Heidegger. Isso porque ela rompe com as discussões de método, aplicando-se imediatamente no plano de uma ontologia do ser finito para, pois, ser compreendida já não como um modo de conhecimento, mas sim como um modo de ser. Chega-se até a via curta por meio de uma súbita inversão da problemática. Conforme Ricoeur (1986 p. 08), a

questão: em que condição um sujeito que conhece pode compreender um texto, ou a história? é substituída pela questão: o que é um ser cujo ser consiste em compreender? O problema hermenêutico torna-se assim uma província da Analítica desse ser, o Dasein, que existe ao compreender.

Ricoeur questiona a possibilidade de se fazer uma ontologia direta, "imediatamente subtraída a toda a exigência metodológica, subtraída, por consequência, ao círculo da interpretação de que ela própria constitui a teoria” (RICOEUR, 1986, p. 8). Aqui, já se pode perceber como Ricoeur vai na contramão da hermenêutica heideggeriana, ao trilhar o caminho da via longa. O filósofo francês, diferentemente de Heidegger, não acredita que a compreensão de si é adquirida de forma imediata por meio de uma análise do ser no mundo. Isso porque essa precisaria passar pela mediação da interpretação das obras nas quais o ser humano se manifesta.

Diferentemente da ontologia da compreensão de Heidegger, que privilegia o caminho curto e conduz diretamente ao problema do ser, Ricoeur privilegia "o caminho longo que passa 
pela linguagem e a reflexão, aceitando o confronto e os desafios das novas ciências do homem e renunciando à tentação de separar verdade e método, compreensão e explicação" (JERVOLINO, 2011, p. 43).

Portanto, Ricoeur acredita que o ponto fundamental a ser levantado no pensamento de Heidegger é a questão do sentido do ser. Dentro da pergunta sobre o sentido, aquele que a realiza será conduzido pelo próprio objeto de sua procura. Em Ser e tempo, Ricoeur compreende que Heidegger revoluciona a teoria do conhecimento, e esta será, desde o início, alterada por uma interrogação que a preceda e que procure abarcar o modo pelo qual um ser encontra o ser, antes mesmo de se lhe opor como um objeto que enfrenta um sujeito (RICOEUR, 1986, p. 89).

A ênfase de Ser e tempo recaía sobre o Dasein. Entretanto, para Ricoeur, esse ser que nós somos não é um objeto para quem existe um objeto, mas um ser no ser. Dasein designa o lugar onde aparece a questão do ser, o lugar da manifestação, e a sua centralidade é apenas a de um ser que compreende o ser. Faz parte da estrutura dele, como ser, ter uma pré-compreensão ontológica do ser. Diante disso, mostrar a constituição do Dasein é apresentar e destacar o fundamento por exibição.

Aqui é criada uma forte oposição entre fundação ontológica e fundação epistemológica. Segundo Ricoeur (1986, p. 89):

Seria apenas uma questão epistemológica, se o problema fosse o dos conceitos de base que regem regiões de objetos particulares, região-natureza, região-vida, regiãolinguagem, região-história. É verdade que a própria ciência procede a uma explicitação como esta dos seus conceitos fundamentais, em particular por uma crise dos fundamentos.

O papel da filosofia de fundação busca destacar os conceitos essenciais determinantes ao entendimento preliminar da região que fornece a base de todos os objetos temáticos de uma ciência, norteando, por ela, toda a investigação positiva. Para Ricoeur, "a aposta da filosofia hermenêutica será, pois, a explicitação deste [...], sendo relativamente a sua constituição de ser" (1986, p. 89). Portanto, tal explicitação não acrescentará nada à metodologia das ciências do espírito. Ela aprofundará, antes, essa metodologia para revelar os fundamentos.

Em Heidegger, a hermenêutica será vista como o caminho que conduz à compreensão. Ele diz:

No compreender, a presença projeta seu ser para possibilidades. Esse ser para possibilidades em compreendendo é um poder-ser que repercute sobre a presença as possibilidades enquanto aberturas. O projetar inerente ao compreender possui a 
possibilidade própria de se elaborar em formas. Chamamos de interpretação essa elaboração. Nela, o compreender apropria-se do que compreende. Na interpretação, o compreender vem a ser ele mesmo e não outra coisa. A interpretação funda-se existencialmente no compreender e não vice-versa. Interpretar não é tomar conhecimento do que se compreendeu, mas elaborar as possibilidades projetadas no compreender. (HEIDEGGER, 2018, p. 209).

A partir de Heidegger, o primado da questão hermenêutica será a compreensão e, para a configuração ou elaboração desta, a interpretação coexistirá; porém, não como meio como ocorreu na hermenêutica tradicional (GRONDIN, 1999, p. 164). Essa é a inversão engendrada pelo filósofo alemão.

Como mostra Ricoeur, a hermenêutica, para Heidegger, não é uma reflexão sobre as ciências do espírito, mas uma explicitação do solo ontológico sobre o qual essas ciências podem ser edificadas e ter a metodologia enraizada.

Essa primeira reviravolta realizada em Ser e tempo arrasta para uma segunda. Para Ricoeur, Dilthey colocou a questão da compreensão ligada ao problema do outrem. Assim, a possibilidade de ascender, por transferência, a um psiquismo estranho dominava as ciências do espírito. Entretanto, Heidegger coloca a questão da compreensão inteiramente desligada do problema da comunicação com outrem. A respeito disso, Ricoeur (1986, p. 90) diz:

Os fundamentos do problema ontológico devem ser procurados na relação do ser com o mundo e não na relação com um outrem, é na relação com a minha situação, na compreensão fundamental da minha posição no ser, que está implicada, a título principal, a compreensão.

Em Dilthey, o conhecimento do psiquismo apresenta uma vantagem inegável sobre o conhecimento da natureza. Heidegger não terá esse pressuposto. Para ele, o outro, tanto como o homem a si mesmo, é mais desconhecido do que qualquer outro fenômeno da natureza. Portanto, se existe uma região do ser onde reina o inautêntico, esta é justamente a relação de cada indivíduo com qualquer outro possível. De acordo com Ricoeur, não é por meio de uma reflexão sobre o ser-com, mas sobre o ser-em, que a ontologia da compreensão pode começar. Não se trata do ser-com um outro, que duplicaria nossa subjetividade, mas do ser-no mundo. Essa mudança do lugar filosófico é tão importante quanto a transferência do problema do método para o problema do ser. A questão mundo ocupa o lugar da questão outrem. Logo, ao mundanizar o compreender, Heidegger o despsicologiza.

Paul Ricoeur entende que aquilo a ser reconquistado com o auxílio da filosofia de Heidegger nessa pretensão do sujeito é a condição de habitante do mundo, condição a partir da 
qual há situação, compreensão e interpretação. Logo, a teoria do compreender deve ser precedida pelo reconhecimento da relação de enraizamento que sustenta a fixação de todo o sistema linguístico, por conseguinte dos textos e dos livros, em qualquer coisa que não é um fenômeno de articulação no discurso (RICOEUR, 1986, p. 91).

Em sua análise em relação ao pensamento de Heidegger, Paul Ricoeur procura explicar cada um dos elementos que fazem parte da tríade situação, compreensão e interpretação. A situação é a necessidade anterior ao compreender. Para Ricoeur, é necessário, antes, encontrarse (bem ou mal), encontrar-se aí e sentir-se (de certa forma), antes mesmo de se orientar. Pelo conhecimento, os seres humanos colocam os objetos diante deles. O sentimento da situação irá preceder esse frente-a-frente, impondo aos homens um mundo.

O segundo elemento da tríade é a compreensão. Conforme Paul Ricoeur, essa não pode ser vista em princípio como um fato da linguagem, da escrita ou do texto. Ela deve ser vista em termos de poder-ser. A compreensão tem como função orientar o ser humano numa situação. $\mathrm{O}$ compreender não se dirige a possuir um fato, mas a uma possibilidade de ser. Em Heidegger, o compreender será essencialmente um projetar, ou um projetar num ser-lançado prévio.

Compreender um texto não é achar um sentido inerte que nele estivesse contido, é revelar a possibilidade a ser indicada pelo texto. Lawrence K. Schmidt mostra que, para Heidegger, a hermenêutica é a compreensão das estruturas, os existenciais, do modo de ser do Dasein. Um desses existenciais será a própria compreensão. Toda compreensão é interpretativa. Schmidt (2012, p. 96) diz:

\footnotetext{
A compreensão é necessariamente interpretação, pois a compreensão começa com a posição prévia, a visão prévia e a concepção prévia. Compreendemos alguma coisa como alguma coisa, mas isto não envolve um círculo vicioso. A compreensão genuína ou correta pode ser obtida quando o intérprete baseia as estruturas prévias da compreensão nas coisas em si. Enquanto compreensão interpretativa, ela é compreensão hermenêutica.
}

Para Heidegger, a compreensão pode ser entendida como entender-se sobre algo que indica menos um saber do que uma habilidade ou um poder (GRONDIN, 1999, p. 160). O entender de uma coisa tem como significado estar apto para ela poder arranjar-se com ela. Essa compreensão para Heidegger será concebida como existencial, isto é, como modo de ser pelo qual o ser humano busca se situar no mundo. 
Ricoeur apresenta o terceiro elemento da tríade: a interpretação. É nela que aparece o momento ontológico que interessa ao exegeta. Entretanto, antes da exegese dos textos, vem a exegese das coisas. Paul Ricoeur diz:

A interpretação, com efeito, é, antes de mais, uma explicitação, um desenvolvimento
da compreensão, desenvolvimento que "não a transforma noutra coisa, mas que a faz
tornar-se ela mesma". Todo o regresso à teoria do conhecimento é, assim, prevenido,
o que é explicitado é o enquanto que se prende com as articulações da experiência.
(RICOEUR, 1986, p. 92).

A Analítica do Dasein dá um sentido ao que pode parecer um fracasso no plano epistemológico, pelo fato de ligar esse aparente fracasso a uma estrutura ontológica intransponível, chamada de pré-compreensão. Ricoeur discorre sobre essa noção. Segundo ele, as relações de familiaridade que se possa ter, por exemplo, com um mundo de instrumentos, podem oferecer uma ideia inicial sobre o significado da aquisição preliminar para o ser humano que busca orientar-se para o uso novo das coisas. Esse caráter de antecipação faz parte do modo de ser de todo ser que compreende historicamente. Portanto, é nos termos da Analítica do Dasein que se deve compreender essa proposição.

A pré-compreensão, como mostra Jean Grondin (1999, p. 159), significa que o Dasein, o ser-aí humano, caracteriza-se por uma interpretação que lhe é peculiar, encontrada antes de qualquer locução ou enunciado. Percebe-se que a hermenêutica antiga sempre procurou argumentar a respeito do círculo - o círculo hermenêutico. Isso ocorreu porque as antecipações de sentido do intérprete eram parte integrante do sentido a interpretar. Logo, para compreender um determinado texto, é necessário ter uma pré-compreensão anterior. Não se pode acabar com a pré-compreensão sem o risco de romper o pacto que se estabelece entre o interpretante e o interpretado, o qual concede ao intérprete o acesso às intenções de sentido do texto.

Contudo, do ponto de vista epistemológico, a implicação do intérprete na coisa que será interpretada aparece como uma fraqueza, uma tara subjetivista, diante da objetividade que parece exigir o ideal de cientificidade. Heidegger tem como objetivo justificar o círculo hermenêutico, apontando que a fraqueza epistemológica aparente deriva de sua força ontológica real: "o círculo mais original, com efeito, é aquele que existe sempre entre a pré-compreensão e a situação intramundana a interpretar” (RICOEUR, 2010, p. 132). Logo, o círculo não pode ser visto como vicioso, ele constitui a condição positiva do conhecimento mais original.

Paul Ricoeur procura instituir uma relação entre a pré-compreensão e o papel dos pressupostos na exegese textual. Esse papel não é, então, mais do que um caso específico dessa 
lei geral da interpretação (RICOEUR, 1986, p. 93). Transposta para o campo da teoria do conhecimento e analisada pela pretensão de objetividade, a pré-compreensão recebe a qualificação pejorativa de preconceito. Segundo a ontologia fundamental, o preconceito só se compreende a partir da estrutura de antecipação do compreender. No plano metodológico, o círculo hermenêutico não é mais do que a sombra projetada dessa estrutura de antecipação. Qualquer ser humano que tenha compreendido essa questão saberá que o elemento decisivo não é abandonar o círculo, mas sim penetrá-lo de forma correta.

Em Ser e tempo, Heidegger introduz a questão da linguagem depois da situação, da compreensão e da interpretação. Nesse contexto, a linguagem permanece uma articulação segunda; da explicitação em enunciados. Contudo, a filiação do enunciado, partindo da compreensão e da explicitação, leva a dizer que sua função primeira é na manifestação, na mostração. Essa função suprema da linguagem não faz mais do que relembrar a sua filiação a partir das estruturas ontológicas que a precedem. Aqui então, Paul Ricoeur irá, de acordo com Heidegger, apresentar a definição de discurso. Para Ricoeur, "o discurso é a articulação daquilo que é compreensão" (RICOEUR, 1986, p. 93). Logo, será necessário recolocar o discurso nas estruturas do ser, e não estas estruturas no discurso. O discurso é entendido como articulação significante da estrutura compreensível do ser-no-mundo.

Nesse sentido, o filósofo francês compreende que está esboçada a passagem à segunda filosofia de Heidegger que não terá mais o Dasein como o foco. O ponto central, agora, será o poder de manifestação da linguagem. Essa passa a ter um papel central no pensamento heideggeriano e será vista como a casa do ser; é nessa habitação do ser que o homem mora (SCHMIDT, 2012, p. 124). A interação do Ser e dos seres humanos acontece na linguagem, e os humanos atingem seu ser essencial na fala. Jean Grondin (1999, p. 173) constata que, nessa virada, Heidegger compreende a linguagem como morada do ser, como se ela tivesse assumido a precedente e insuperável revelação do ser. Sobre a passagem à segunda filosofia de Heidegger, Ricoeur diz:

Mas, desde o Sein und zeit (Ser e tempo), o dizer (reden) parece superior ao falar (sprechen). O dizer designa a constituição existencial, e o falar, o seu aspecto mundano que cai na empiria. É por isso que a primeira determinação do dizer não é o falar, mas o par ouvir-calar-se. Também aqui Heidegger ilude a maneira vulgar, e mesmo linguística, de colocar, na primeira etapa, a operação de falar (locução, interlocução). Compreender é ouvir. Por outras palavras, a minha primeira relação com a fala não quer dizer que eu a produza, mas que a receba. "O ouvir é constitutivo do discurso". Esta prioridade da escuta marca a relação fundamental da fala com a abertura ao mundo e ao outrem. As consequências metodológicas são consideráveis: a linguística, a semiologia, a filosofia da linguagem ficam, inelutavelmente, ao nível 
do falar e não atingem o do dizer. Neste sentido, a filosofia fundamental já não traz nada de novo à linguística que ela não acrescente à exegese. Enquanto o falar remete para o homem falante, o dizer remete para as coisas ditas. (RICOEUR, 1986, p. 94).

Conforme Ricoeur, a aporia manifesta na dissociação entre explicar e compreender não foi resolvida. Ela foi simplesmente deslocada e, por isso mesmo, agravada. A aporia não se encontra mais na epistemologia, entre duas modalidades de conhecer, mas é situada entre a ontologia e a epistemologia, tomadas em bloco. Com a filosofia de Heidegger, não se deixou de praticar o movimento de retorno aos fundamentos, mas percebeu-se uma incapacidade de proceder uma volta que, da ontologia fundamental, levaria à questão propriamente epistemológica do estatuto das ciências do espírito.

Ora, uma filosofia que rompe o diálogo com as ciências já não se dirige, senão, a si mesma. Além do mais, é apenas sobre o trajeto de volta que se mostra a pretensão de manter as questões de exegese e, em geral, de crítica histórica como questões derivadas. Enquanto não se proceder efetivamente a essa derivação, permanecerá problemática a própria passagem para as questões de fundação.

\section{CONCLUSÃO}

Ricoeur compreende o ser humano como um animal hermenêutico. Ele toma de Heidegger a convicção de que as estruturas do compreender e do interpretar estão no coração do ser e da ação. Heidegger é o filósofo que realiza o radical movimento hermenêutico da epistemologia para a ontologia. Em Heidegger, a questão das ciências do espírito realiza, primeiramente, uma interrogação ontológica sobre o modo de ser daquele que existe somente pela compreensão. O Dasein não é, primeiramente, um sujeito para o qual os objetos existem, mas sim um ser sobre o qual já temos uma pré-compreensão. Não pode haver compreensão de si sem interpretação. Ricoeur adota a virada ontológica da hermenêutica que se preocupa menos com as questões de método e com a intenção do autor, e mais com o explicitar a nossa maneira de habitar o mundo.

Para Heidegger a epistemologia está subordinada à ontologia. Entretanto, segundo Ricoeur, existe uma questão que não foi resolvida na teoria do filósofo alemão: como tomar consciência de uma questão crítica em geral, no contexto de uma hermenêutica fundamental? Para Paul Ricoeur, é sobre esse trajeto de volta que poderia atestar-se e manifestar-se a afirmação segundo a qual o círculo hermenêutico, no sentido dos exegetas, está fundado sobre 
a estrutura de antecipação da compreensão no plano ontológico fundamental. Mas a hermenêutica ontológica parece incapaz, por razões estruturais, de desvendar essa problemática de retorno. No próprio Heidegger, a questão é abandonada desde que é posta. Ricoeur diz:

\footnotetext{
Lê-se isto no Ser e tempo: "O círculo característico da compreensão [...] contém em si uma possibilidade autêntica do conhecer mais original, só é apreendida corretamente, se a explicitação considerar como sua tarefa primeira, permanente e última, não deixar que se lhe imponham as suas aquisições e pontos de vistas preliminares e as suas antecipações por quaisquer ideias enviesadas e noções populares, mas assegurar o seu tema científico pelo desenvolvimento das suas antecipações segundo as próprias coisas”. (RICOEUR, 1986, p. 95).
}

É colocada, no início, a diferenciação entre a antecipação conforme as coisas mesmas e uma antecipação que seria proveniente das ideias transversais e dos conceitos populares. Ricoeur percebe o aparecimento de um problema aqui. Ele questiona como é possível avançar, se na sequência se afirma que os pressupostos ontológicos de todo conhecimento histórico ultrapassam a ideia de rigor presente nas ciências exatas e que se abole toda a questão do rigor específico às ciências históricas. Logo, a preocupação em enraizar mais profundamente o círculo hermenêutico é que toda epistemologia impede que se repita a questão epistemológica depois da ontologia. Conforme o pensador francês, essa afirmação, mais uma vez, apresenta o problema da aporia.

\section{REFERÊNCIAS}

GRONDIN, Jean. Introdução à hermenêutica filosófica. São Leopoldo: Unisinos, 1999. HEIDEGGER, Martin. Ser e tempo. Petrópolis: Vozes, 2003.

MAC DOWELL, João. A gênese da ontologia fundamental de Martin Heidegger. São Paulo: Editora Herder, 1970.

MAC DOWELL, João. Apostila sobre Ser e Tempo. Belo Horizonte: FAJE, 2011. (apostila não publicada).

RICOEUR, Paul. Du texte à l'action: essais d'herméneutique II. Paris: Éditions du Seuil, 1986.

RICOEUR, Paul. Écrits et conférences 2 - Herméneutique. Paris: Éditions du Seuil, 2010.

RICOEUR, Paul. O conflito das interpretações. Porto: Rés-Editora, 1988.

ROHDEN, Luiz. Hermenêutica filosófica: entre a linguagem da experiência e a experiência da linguagem. São Leopoldo: Unisinos, 2002.

SCHMIDT, Lawrence K. Hermenêutica. Petrópolis: Vozes, 2012. 